I Universidade Nova de Lisboa (UNL), Faculdade de Ciências Sociais e Humanas,

Centro em Rede de Investigação em Antropologia (CRIA), Lisboa, Portugal

joao.leal@fcsh.unl.pt

https://orcid.org/0000-0002-0513-103X

João Leal'

\title{
OS ENCANTADOS NAS FESTAS DO DIVINO: ESTRUTURA E ANTIESTRUTURA
}

De entre os seus numerosos interesses de pesquisa - que incluíram por exemplo o tambor de crioula (Ferretti, 2002) - aquele que ocupou um lugar central na pesquisa de Sergio Ferretti foi o tambor de mina, a religião afro-brasileira predominante em São Luís (Maranhão). Esse interesse possui, entre outras, duas características importantes. Incide sobre uma religião que, não obstante a sua importância, tem ocupado um lugar relativamente secundário na antropologia das religiões afro-brasileiras (Engler \& Brito, 20I6). De fato, durante muito tempo, a bibliografia disponível sobre o tambor de mina limitou-se aos estudos pioneiros de Nunes Pereira (I979) e de Octávio Eduardo (I948), e foi preciso esperar pelas monografias de Sergio Ferretti (2009; I995) sobre a Casa das Minas, editadas a partir dos anos I980, para que o tambor de mina ganhasse maior projeção e atualidade na antropologia das religiões afro-brasileiras. ${ }^{\mathrm{I}}$ Um segundo traço importante da pesquisa de Ferretti prende-se ao destaque dado ao perfil sincrético do tambor de mina e, em particular, à Casa das Minas, o terreiro de matriz jeje onde Ferretti focou a sua pesquisa. Se na sua primeira monografia (Querebentã de Zomadônu. Etnografia da Casa das Minas do Maranhão) esse perfil sincrético é tratado de forma sobretudo descritiva - em particular no capítulo intitulado "O ciclo das festas" -, a segunda monografia (Repensando o sincretismo) é inteiramente consagrada ao tópico. Depois de uma primeira parte em que procede a uma discussão teórica do conceito de sincretismo, Ferretti dedica a segunda parte do livro a uma análise das principais modalidades 
de sincretismo presentes na Casa das Minas. Essa análise é marcada por reiteradas críticas a Roger Bastide (I960) que, tendo escrito sobre a Casa das Minas em As religiões africanas no Brasil, a analisara à luz das suas preferências africanistas (mesmo que isso tivesse significado o silenciamento das evidências sincréticas disponíveis desde I948 na monografia de Octávio Eduardo, que Bastide conhecia). De fato, contrariamente a Bastide, para quem a máxima fidelidade à África seria incompatível com o sincretismo, a conclusão de Ferretti é a de que o máximo de africanismo e o máximo de sincretismo podem coexistir - como acontecia na Casa das Minas:

Constatamos que a Casa das Minas é muito tradicional e, ao mesmo tempo, altamente sincretizada. A presença do sincretismo não descaracteriza a tradicionalidade da religião. Não há portanto fronteiras nitidamente demarcadas entre sincretismo e tradição, A originalidade principal do nosso trabalho consiste justamente em analisar o sincretismo num dos grupos religiosos afro-brasileiros mais tradicionais (Ferretti, I995: 217).

O relevo dado por Ferretti ao tema do sincretismo na sua pesquisa sobre a Casa das Minas deve ser evidenciado. Como ele próprio escreveu em Repensando o sincretismo, depois de uma presença destacada ao longo dos anos 1930 a I960, o tema havia praticamente desaparecido da antropologia das religiões afro-brasileiras a partir dos anos I970. Foi justamente por intermédio da monografia de Ferretti - e também de Águas do rei, de Ordep Serra (I995) - que o conceito regressou à antropologia das religiões afro-brasileiras, na qual voltou a ocupar desde então lugar mais destacado (v. Leal, 2017: 367-374).

No tratamento que consagra ao tema em Repensando o sincretismo, Ferretti dá particular destaque - tal como antes em Querebentã de Zomadônu - a festas em que as articulações entre o tambor de mina e o catolicismo são mais estruturantes. Entre elas ocupa lugar proeminente a festa do Divino Espírito Santo, com presença relevante em São Luís, onde mais de 80 festividades são celebradas todos os anos, a maioria delas em terreiros de tambor de mina (Gonçalves \& Leal, 20I6). Inicialmente trabalhadas na sua pesquisa sobre a Casa das Minas, as festas do Divino - dada essa sua importância no menu ritual do tambor de mina - tornaram-se, a partir dos anos 2000, presença recorrente na produção antropológica de Sergio Ferretti, que lhes consagrou numerosos ensaios (e.g. Ferretti, I999, 2005, 2007).

Foi a leitura desses ensaios - assim como das monografias de Ferretti sobre a Casa das Minas - que "puxou" a minha pesquisa sobre festas do Divino para São Luís. Tinha anteriormente pesquisado sobre as festas do Espírito Santo nos Açores (Leal, I994) e entre a diáspora açoriana na América do Norte (Leal, 20I I: I3-82; Leal, 20I7: 89-224) e estava interessado em alargar a análise das festas para o Brasil. Depois de ter lido Ferretti, São Luís tornou-se a escolha óbvia: de todo o Brasil, só aí, as festas se articulavam com uma religião de matriz africana. Em consequência, conduzi entre 20 I I e 20I4, cerca de nove 
meses de pesquisa em São Luís, da qual resultou a segunda parte do livro 0 culto do Divino. Migrações e transformações (Leal, 2017: 225-376). Faz pois todo o sentido que seja sobre as festas do Divino em terreiros de tambor de mina - e sobre os seus modos de articulação - que se organize este artigo. Por seu intermédio homenageio não só o Ferretti cuja leitura me empurrou para São Luís, mas também o Ferretti que ao longo da minha pesquisa foi incansavelmente generoso no apoio que me deu, fornecendo contatos, apresentando-me em vários terreiros, esclarecendo dúvidas, lendo e comentando os textos que fui escrevendo.

O foco do artigo é constituído pela oscilação que é possível detectar nas festas do Divino de São Luís entre segmentos rituais colocados sob o signo do decoro, da ordem e da solenidade rituais e segmentos rituais colocados, inversamente, sob o signo da brincadeira, do excesso e da transgressão. Essa oscilação pode encontrar-se em outras festas. Assim, em Portugal, ela foi trabalhada por Pierre Sanchis em torno das romarias do norte do país que, segundo o autor, estruturar-se-iam em torno dos polos contraditórios da celebração e do arraial. A celebração compreenderia a missa e a procissão, colocadas sob o signo da autoridade da Igreja. A solenidade e a contenção - juntamente com a hierarquia - seriam os seus valores dominantes. A missa corresponderia a uma espécie de "suspensão do tempo festivo" colocada sob o signo da "austeridade" e do "congelamento dos movimentos" (Sanchis, I983: 99). "Austeridade" é também a expressão retomada por Sanchis a propósito da procissão que, mesmo quando se dá como espetáculo, "é informada pela ortodoxia oficial, performada sob o controlo da autoridade" e não daria "nenhum lugar à espontaneidade e à improvisação" (Sanchis, I983: I27). Simultaneamente, porém, tem lugar o arraial, um espaço, inversamente, controlado pelo povo: "Aí se canta, aí se dança, aí se toca música; aí se come, aí se fazem trocas e comércio; aí se processam encontros cuja significação erótica é particularmente marcada" (Sanchis, I983: I43), sendo os seus valores "a liberdade relativamente às regras; a ausência de trabalho, a gratuitidade". Por isso a Igreja é a primeira a denunciar os excessos: "os nossos católicos só compreendem uma festa quando há muito fogo de artifício, muita música, um arraial, muito vinho e muita desordem" (Sanchis, I983: I68). Em consequência, é à luz das teorias transgressoras do ritual - tal como foram formuladas por Georges Bataille (I967) e por Jean Duvignaud (I973) - que Sanchis analisa a lógica do arraial.

No Brasil, esta oscilação entre decoro cerimonial e excesso ritual foi também documentada para várias festas. Entre elas encontra-se, por exemplo, a folias de reis. Assim, para Daniel Bitter (20 Io), as folias de reis do Rio de Janeiro estruturar-se-iam em torno da oscilação entre dois tipos contrastantes de personagens e objetos rituais: de um lado os foliões e a bandeira, do outro os palhaços e a máscara. Segundo o autor, "a brincadeira do palhaço é [...] o lugar potencial da subversão, da desordem, [...] da criatividade, em contraste 
com a formalidade e a solenidade do canto, da música, das palavras e dos gestos dos foliões" (Bitter, 20I0: I75). Ou, em outra formulação, "a máscara é 'grotesca', o que se evidencia através de caracteres formais que lhe são próprios, como exagero, excesso, hiperbolismo e profusão", enquanto "a bandeira [...] é sublime [...], sua forma rigorosamente ordenada, e a simetria é a estrutura formal predominante" (Bitter, 20I0: 205). Wagner Chaves (2013: I48) procede a uma caracterização idêntica das folias de reis de Minas Gerais, contrapondo o espaço da casa - onde reina a folia - ao espaço da rua - onde dominam os palhaços: "de um lado, a seriedade e formalidade do canto. [...]. De outro lado, a chula, a rua, o espaço público - lugar de brincadeira, do descontrole, da liminaridade, e do perigo".

Um dos objetivos principais do presente artigo é justamente o de examinar essa oscilação entre decoro e ordem e excesso e transgressão - ou, adaptando uma terminologia de Victor Turner (I969), entre estrutura e antiestrutura - no caso das festas do Divino de São Luís. Tentarei mostrar como também nessas festas essa oscilação tem caráter estruturante, organizada em torno de dois territórios rituais distintos: a tribuna, situada do lado do decoro e da ordem, e o mastro, situado do lado do excesso e da transgressão. Um segundo objetivo do artigo é mostrar como essa oscilação é enfatizada e coproduzida por meio de um dos aspectos mais importantes do desenho sincrético das festas: a participação dos encantados - designação genérica dada às entidades espirituais que baixam no tambor de mina - nas festas. De fato, os encantados não só participam em plano de relevo nas festas do Divino, como sua participação se faz de acordo com sua associação a valores e comportamentos marcados ora pela solenidade e pela hierarquia, ora, inversamente, pelo excesso e pela desordem. ${ }^{2}$ Pode-se, portanto, falar a respeito de formas de articulação entre as festas do Divino e o tambor de mina, de sua natureza processual. Em vez de estabelecer compatibilidades substantivas - como as que fazem equivaler entre si entidades espirituais provenientes de gêneros religiosos distintos -, elas estabelecem compatibilidades entre modos de performance ritual. Deve também ser enfatizado o modo como essas compatibilidades fazem interagir dois gêneros religiosos que são dessa forma conectados entre si e, simultaneamente, mantêm as suas diferenças.

Para a argumentação apresentada neste artigo basear-me-ei sobretudo em informação recolhida em quatro dos sete terreiros que tive oportunidade de pesquisar: Casa Ilê Ashé Obá Izô, Casa de Iemanjá, Jardim da Encantaria e Terreiro Fé em Deus. Como já demonstrei (Leal, 20I7), os modos de articulação entre festas do Divino e tambor de mina apresentam certa variabilidade de terreiro para terreiro e é neles que a presença dos encantados nas festas é mais relevante. ${ }^{3}$ 


\section{A TRIBUNA E O MASTRO}

As festas do Divino em São Luís dividem-se em dois grandes grupos: as festas que convergem para o domingo de Pentecostes e que celebram exclusivamente o Espírito Santo, e as festas que se realizam ao longo do ano e que homenageiam simultaneamente o Espírito Santo e o santo (ou santa, ou invocação de Nossa Senhora) que é comemorado no dia principal da festa. Independentemente dessa diferença, as festas do Divino caracterizam-se por um roteiro ritual relativamente estável, que passo a apresentar. ${ }^{4}$

O Espírito Santo é usualmente representado - em conjunto com um pombo de madeira e com a bandeira do Espírito Santo - por uma coroa em latão (ou, mais raramente, em prata), encimada por uma pomba e acompanhada de um cetro. Esses símbolos são instalados na tribuna, um altar ricamente decorado no qual se centra parte importante dos festejos. Como em muitos outros festejos populares brasileiros, a festa do Divino surge ainda associada a um mastro, um tronco de árvore decorado, geralmente encimado por uma pequena bandeira, que, além de assinalar o lugar e o tempo da festa, simboliza também o Espírito Santo.

Nas festas têm papel de grande importância os impérios: crianças e pré-adolescentes de ambos os sexos, que envergam roupas de gala inspiradas em trajes de corte e desempenham os cargos de imperador e imperatriz, mordomo e mordoma régio(a) e mordomo e mordoma-mor. Esses cargos são bancados - isto é, patrocinados e pagos - por adultos, geralmente pais ou outros parentes próximos das crianças.

A par dos impérios, o outro grupo de protagonistas mais importante das festas é constituído pelas caixeiras: agrupamentos de oito ou mais mulheres - dirigidas por uma caixeira régia - que, por meio de cânticos acompanhados pelas caixas, asseguram a direção musical dos festejos e se encarregam de louvar o Espírito Santo e o santo (ou santa, ou invocação de Nossa Senhora) celebrado em conjunto com o Divino (Gouveia, 200 I; Pacheco, Gouveia \& Abreu, 2005; Barbosa, 2006). Se a articulação das festas do Divino com esse tipo de agrupamentos musicais (geralmente conhecidas pela designação de folias) é recorrente no Brasil, é exclusiva do Maranhão a solução de feminização desse desempenho ritual.

A sequência das festas apresenta também certa regularidade. O seu início é assinalado pela abertura da tribuna que é seguida, algum tempo depois, pelo buscamento ${ }^{5}$ e pelo levantamento do mastro. Estes dois últimos rituais procedem ao transporte do mastro para o local de realização da festa e são geralmente muito concorridos e com larga participação popular. Uma vez levantado o mastro, realizam-se, nos dias subsequentes, alvoradas junto à tribuna, no decurso das quais as caixeiras homenageiam o Espírito Santo e outras entidades católicas. 
O dia da festa - que pode realizar-se de uma semana a dez dias depois do buscamento e do levantamento do mastro - compreende um conjunto diversificado de rituais. Dentre eles destaca-se a ida à missa dos impérios, em geral seguida de um cortejo. Uma vez de regresso ao recinto da festa, realiza-se a cerimônia da recepção da coroa e dos impérios, que são depois sentados na tribuna onde recebem as homenagens das caixeiras. Terminado esse ritual, tem lugar um almoço que começa por juntar os impérios e as caixeiras, mas abre-se depois para todos os convidados e outras pessoas que queiram participar dos festejos. Esse almoço é muito concorrido, pode reunir centenas de pessoas, e é um dos segmentos rituais mais dispendiosos e também mais importantes no prestígio e na reputação de uma festa. Durante a tarde do dia da festa, enquanto as caixeiras vão entoando vários cânticos junto à tribuna, tem lugar uma radiola de reggae que pode ser acompanhada pela realização de outras atividades festivas, como o tambor de crioula.

No dia seguinte ao da festa, faz-se o derrubamento do mastro que, tal como seu buscamento e seu levantamento, tem larga participação popular. Realiza-se depois o repasse das posses (designação dada aos trajes e outros adereços cerimoniais) entre as crianças dos impérios, acompanhado de sua investidura nos cargos que desempenharão no ano seguinte. Uma vez concluído o repasse das posses, as caixeiras procedem ao encerramento da tribuna, no decurso do qual a festa é dada por terminada, e o Espírito Santo - depois de se ter feito presente durante todo o período da festa - regressa a sua morada divina. Por fim, no dia seguinte, pode realizar-se o carimbó das caixeiras, um almoço que decorre em ambiente de marcada informalidade e se destina às caixeiras e a outras pessoas próximas do festeiro.

Caracterizadas pelos traços gerais que acabamos de passar em revista, as festas do Divino têm na tribuna e no mastro dois espaços importantes de sua topografia ritual. A tribuna é geralmente instalada no salão principal do terreiro em que tem lugar a festa. Além de acolher a coroa e outros símbolos do Espírito Santo - assim como a imagem do santo (ou santa, ou invocação de Nossa Senhora) que é celebrado em conjunto com o Espírito Santo -, compreende um conjunto de tronos laterais onde se sentam as crianças dos impérios. Inspirada no modelo do altar barroco e ricamente decorada, a tribuna é o lugar por excelência da devoção ao Espírito Santo. É lá que - sob a direção dos cantos das caixeiras - as crianças dos impérios são empossadas nas suas funções e suas promessas são aceitas, e é lá que, no decurso da festa, as caixeiras entoam os cânticos que homenageiam o Espírito Santo e outras entidades espirituais católicas.

Quanto ao mastro, situa-se geralmente no exterior do terreiro - ou na rua, ou no quintal (no caso dos terreiros que o têm). É geralmente decorado com murta, frutas e refrigerantes - que são disputados pelos presentes após seu derrubamento -, e, diferentemente da tribuna, seu protagonismo ritual 
durante a festa limita-se aos segmentos rituais expressamente centrados nele (buscamento, levantamento e derrubamento do mastro). Não deixa, entretanto, de possuir um conjunto de significações religiosas geralmente postas em evidência nos cantos das caixeiras. Além de simbolizar o Espírito Santo, é tratado por "Manoel da Vera Cruz" ou "Oliveira", sendo assimilado a Jesus Cristo e é também visto como a representação da árvore em que pousou a pomba que anunciou a Noé o fim do dilúvio.

Definindo dois territórios centrais das festas do Divino, a tribuna e o mastro estão associados a valores e comportamentos contrastantes. A tribuna, espaço por excelência de devoção ao Espírito Santo, é também um espaço marcado pela solenidade e pela hierarquia. Um dos termos por que é conhecida "tribunal" - acentua essa sua dimensão. Como me disse dona Jacy Serra, caixeira régia em São Luís, justificando o recurso a essa expressão, "é porque [lá] está os tronos, está as majestades, está a coroa, é uma coisa mais alta, mais definitiva". Esses valores de decoro cerimonial são particularmente evidentes na abertura da tribuna, na recepção da coroa e dos impérios depois da missa, no repasse das posses e no encerramento da tribuna, que são acompanhados em silêncio por numerosa assistência e marcados por elaborado cerimonialismo que as caixeiras se encarregam de fazer respeitar. O repasse das posses e o encerramento da tribuna, em particular, são considerados pelas caixeiras da maior "responsabilidade": tudo deve ser feito de acordo com o previsto no roteiro ritual consagrado, sob o risco de, se alguma coisa correr mal, tal poder ter consequências funestas sobre algum participante da festa. As alvoradas asseguradas junto à coroa pelas caixeiras não têm uma etiqueta cerimonial tão marcada, mas são, de qualquer modo, espaços centrais para louvar o Espírito Santo e outras entidades espirituais católicas homenageadas no decurso da festa.

Em contraste com a associação da tribuna à devoção e ao decoro, os segmentos relacionados com o mastro são marcados pela brincadeira, pelo excesso e pela transgressão. A música mais cerimonial das caixeiras - que também acompanham esses segmentos rituais - dá lugar, ou é abafada, pela música de uma pequena banda de sopros e percussões que executa várias composições festivas. No buscamento, as pessoas dançam enquanto acompanham o cortejo, circulam vinho e outras bebidas entre os presentes e multiplicam-se os trocadilhos de índole sexual sobre o mastro (tratado jocosamente por "pau"). O levantamento do mastro prolonga essa atmosfera de licenciosidade: mais uma vez torna-se difícil ouvir a música das caixeiras, e a relativa solenidade do batizado do mastro - que é dirigido pelas caixeiras e no qual participam os impérios e os padrinhos e madrinhas do mastro - é abafada pela atmosfera festiva e ruidosa dominante entre as centenas de pessoas que esperam com expectativa que o mastro seja erguido. Uma vez ele levantado, mantém-se o ambiento festivo, e, como já referi, em muito terreiros pode ter lugar um tambor de crioula ou uma radiola de reggae. É o mesmo registo festivo e ruidoso 
que caracteriza o derrubamento do mastro: quando esse antecede, como acontece em muitos terreiros, o repasse das posses e o encerramento da tribuna, o contraste entre essas duas dimensões das festas do Divino - a que sublinha princípios de etiqueta e hierarquia e a que abre para a brincadeira e para o excesso - não poderia ser mais evidente.

\section{OS ENCANTADOS NA FESTA}

O fato de as festas do Divino terem lugar em terreiros de tambor de mina está associado a um conjunto de articulações entre ambos os gêneros rituais (Ferretti, I995; Leal, 2017). Essas articulações decorrem da instabilidade teológica das festas do Divino - ao mesmo tempo que se situam no território da devoção católica ao Espírito Santo e a outras entidades espirituais católicas; elas podem também situar-se no terreno da obrigação religiosa para com as entidades espirituais do tambor de mina.

De fato, a realização das festas tanto pode resultar de uma promessa ou da devoção católica do pai ou mãe de santo como do pedido ou, em alguns casos, da devoção de um dos seus encantados, que solicita a realização da festa. O mesmo se passa com os adultos que bancam os impérios e que tanto o podem fazer em resultado de uma promessa ao Espírito Santo como em resultado de um pedido de um encantado. Algumas caixeiras também são devotas do Espírito Santo por via de algum pedido ou acordo estabelecido com um encantado.

Em consequência do papel que desempenham nas decisões relacionadas com a sua realização, as entidades espirituais do tambor de mina têm presença importante nas festas. Elas podem, por exemplo, associar-se à definição de alguns dos seus aspetos organizativos, como a definição da cor da festa, que varia de ano para ano. Algumas inovações introduzidas nas festas são muitas vezes apresentadas como o resultado do pedido de um encantado. Mas é sobretudo por meio da sua intervenção em alguns segmentos rituais que a participação das entidades espirituais do tambor de mina nas festas do Divino é mais significativa. Essa participação pode ocorrer em vários momentos das festas, relacionados ora com a tribuna, ora com o mastro. Tem lugar, mais generalizadamente, na recepção da coroa e dos impérios após a missa ou, em alguns terreiros, na abertura e no encerramento da tribuna. Caracteriza-se ainda por outras expressões, relacionadas sobretudo com a equivalência estabelecida entre alguns encantados e as crianças dos impérios. E ocorre também no buscamento, no levantamento e no derrubamento do mastro.

Nos segmentos rituais relacionados com a tribuna, as entidades espirituais que se fazem presentes são em menor número e são entidades espirituais que baixam no pai ou na mãe de santo do terreiro em que tem lugar a festa ou em algumas filhas de santo da casa. Nos segmentos rituais relacionados com o mastro, a participação de entidades espirituais do tambor de mina é mais 
abrangente: além de entidades espirituais ligadas ao terreiro que organiza a festa, participam muitas entidades espirituais de outros terreiros. Não é essa, contudo, a única diferença relativa à participação dos encantados nas festas. As entidades espirituais que se fazem presentes nos segmentos rituais relacionados com a tribuna e com o mastro estão elas próprias situadas ora do lado do excesso e da brincadeira - no caso do buscamento, do levantamento e do derrubamento do mastro -, ora do lado da hierarquia e da contenção - no caso dos segmentos rituais relacionados com a tribuna.

Para entender essa participação diferenciada dos encantados nas festas do Divino, é importante levar em conta alguns princípios que presidem a organização do panteão do tambor de mina, caracterizado pela multiplicidade de entidades espirituais que o integram, que se distribuem por diferentes categorias (ou grandes grupos). Entre esses grupos avulta desde logo o constituído por entidades de origem africana, como os voduns jeje e os orixás iorubá. Num segundo grupo encontram-se encantados de origem europeia conhecidos pela designação de nobres ou gentis (como o rei Sebastião ou dom Luís). Num terceiro grupo estão os caboclos, com caraterísticas genéricas similares àquelas que encontramos em outras religiões afro-brasileiras. Os turcos, as princesas e os "índios e selvagens" (Ferretti, 2000: 74) completam o panteão do tambor de mina. ${ }^{6}$ Os turcos têm origem nobre, mas optaram por renunciar a essa condição, passando a viver em aldeias indígenas, onde casaram e tiveram filhos. Quanto às princesas, têm dupla filiação nas tobossi jeje - espíritos femininos infantis - e no imaginário real europeu (Parés, I997: I8I). Finalmente, os "índios e selvagens", entre os quais avultam os surrupiras, são "entidades pouco civilizadas, que não falam bem o português" (Ferretti, 2000: 74) e que apenas se manifestam uma vez por ano num toque de tambor - conhecido por tambor de borá ou tambor de índio - que lhes é especialmente dedicado.

Essas diferentes divindades e entidades religiosas estão tendencialmente organizadas de modo hierárquico: os voduns e orixás situam-se no topo da hierarquia, depois vêm os nobres e princesas, e por fim os caboclos e os surrupiras. Quanto aos turcos, ocupam posição instável entre os nobres e os caboclos. Um dos critérios para essa organização hierárquica tem a ver com a proximidade da "matéria": os encantados que ocupam as posições do topo da hierarquia - também conhecidos como "entidades de toalha" - situam-se num plano mais "espiritual", ao passo que aquelas que estão situadas na base estão mais perto da matéria. Por isso, voduns, orixás e nobres baixam menos frequentemente, e os caboclos, mais assíduos, são também as entidades que se manifestam com mais frequência em seus "cavalos", muitas vezes fora de um contexto ritual, em associação com comportamentos considerados excessivos.

Não é esse, porém o único critério que permite distinguir hierarquicamente os diferentes grupos de encantados. Simultaneamente - e esse é o ponto mais importante para o argumento deste artigo - essa hierarquia se exprime 
também no modo como algumas entidades (voduns, orixás, nobres e princesas) se colocam do lado da contenção e do decoro rituais ao passo que outras (os caboclos e os surrupiras) estão do lado do excesso e da transgressão. Essa distinção é sobretudo evidente nas diferentes expressões que o transe assume no tambor de mina. Assim, o transe calmo e solene de voduns, orixás, nobres e princesas contrasta com a forma mais tumultuosa como os caboclos baixam. Às coreografias ordenadas dos primeiros opõem-se as coreografias espontâneas e mais caóticas dos segundos. O próprio vestuário que identifica cada um desses grupos de entidades é diferente: num toque para voduns e/ou para nobres, todas as filhas e filhos de santo vestem igual e usam roupas que combinam no máximo duas cores. Num toque para caboclos, cada dançante se veste de modo diferente, e a policromia da roupa, assim como sua exuberância, é dominante.

A associação dos caboclos ao excesso e à transgressão é mais evidente no caso de duas categorias distintas de caboclos. Uma é a dos caboclos farristas, que integram uma categoria especial de caboclos, caracterizada por comportamento hedonista e excessivo. Gostam de "farra", bebem muito, fumam e adotam falas e comportamentos marcados pelo excesso, que as filhas e os filhos de santo, quando puros, jamais adotariam. ${ }^{7}$ A outra é dos caboclos da mata. Originários do tambor da mata (proveniente de Codó), os caboclos dessa linha são "entidades caboclas menos civilizadas [...] que vivem, geralmente, em lugares afastados das grandes cidades" (Ferretti, 2000: 8I) e que dançam de modo mais tumultuoso e agitado. Deve-se ainda enfatizar a ideia de que muitos caboclos diferentemente do que sucede com voduns, orixás e nobres, que se consideram devotos dos santos católicos a que aparecem associados (Ferretti, 2000: I07) - ignoram ou hostilizam entidades católicas, mesmo quando cultuadas nos terreiros.

É de acordo com essas características que as entidades espirituais do tambor de mina participam nas festas do Divino. Assim, voduns, orixás e nobres movimentam-se preferencialmente no espaço da tribuna, também ele associado à contenção e à hierarquia. Quanto aos caboclos, movimentam-se preferencialmente no espaço do mastro, associado à brincadeira e à desordem.

Alguns exemplos podem ser dados. Assim, a associação privilegiada dos voduns, orixás e nobres à tribuna passa sobretudo pela recepção da coroa e dos impérios após a missa. Em muito terreiros é de fato uma das entidades que baixa no pai ou na mãe de santo que recebe a coroa das mãos do imperador (ou da imperatriz) e que a conduz e instala na tribuna, acompanhando os primeiros cantos entoados pelas caixeiras e recebendo as homenagens dos filhos e das filhas de santo da casa, assim como de outras pessoas presentes. Por vezes participam também dessa cerimônia outros encantados, geralmente da mesma família da entidade que baixa no pai ou mãe de santo. Assim, na casa Ilê Ashé Obá Izô, a festa do Divino homenageia São Luís e o Espírito Santo. A recepção da coroa e dos impérios depois da missa está aí geralmente a cargo 
de dom Luís (incorporado no pai de santo) assessorado por dom Henrique e Luisinho, dois nobres da família de dom Luís. A Casa de Iemanjá celebra a festa na mesma data. Mas aí a recepção da coroa está a cargo de um vodum, Toy Agongono, e de um nobre da família de dom Luís, dom Lauro das Mercês. ${ }^{8}$ Nessa casa, de resto, a chegada da coroa da missa é assinalada pela realização de um breve toque de tambor de mina junto à tribuna. Na casa Jardim da Encantaria, dirigida por pai Clemente, a entidade que recebe a coroa é variável: geralmente é Averequete, um vodum - mas no ano em que assisti à festa foi Oxum. Embora menos generalizada, a presença dos encantados de toalha pode também verificar-se na abertura ou, mais raramente, no encerramento da tribuna. Assim, na abertura da tribuna da casa Ilê Ashé Obá Izô fazem-se em geral presentes duas entidades nobres da família de dom Luís - dom Henrique e Luisinho. E na Casa de pai Clemente, é também Averequete - ou Oxum - que participa no encerramento da tribuna.

Em alguns terreiros essa associação dos encantados à tribuna faz-se por intermédio das crianças dos impérios que, embora não saibam, representam alguns desses encantados, geralmente nobres ou princesas. É o que acontece na Casa de Iemanjá, onde o imperador representa dom Luís, e a imperatriz, a sua esposa. Quanto às restantes crianças dos impérios, reinam também "em nome de D. Luís" (Oliveira, I989: 39). É o que se passa também no terreiro Fé em Deus. Aí, a par de algumas crianças dos impérios que representam figuras católicas, outras representam entidades do tambor de mina, particularmente princesas e entidades nobres: segundo a mãe de santo do terreiro, citada por Cláudia Gouveia (I997: 48), "são elas que se sentam no trono".

Outra expressão dessa associação entre as princesas e a tribuna encontra-se nos toques de tambor de mina associados à festa do Divino. De fato, na maioria dos terreiros, as festas do Divino fazem parte de um conjunto ritual mais amplo que inclui, além de algumas obrigações internas à casa, toques de tambor de mina que homenageiam diferentes entidades. Alguns desses toques realizam-se em frente à tribuna que, depois de seu encerramento formal, só é efetivamente desmontada ao fim de sete dias. Durante esse período, ela se mantém tal qual como na festa: com a coroa, o pombo e outros símbolos do Divino Espírito Santo e também com os trajes dos impérios, cada um no trono respectivo. É justamente diante da tribuna - que é alumiada para o efeito - que têm lugar os toques de tambor de mina que se realizam após o encerramento formal da festa, em meio aos quais encontra-se um toque para princesas. Em alguns terreiros, como a Casa de Iemanjá e a Casa Ilê Ashé Obá Izô, é estabelecida equivalência entre as princesas - em sua qualidade de entidades femininas infantis nobres - e as crianças dos impérios: umas e outras têm em comum o fato de ser crianças e seu estatuto de nobreza. Em consequência, as crianças dos impérios assistem, sentadas na tribuna, à parte inicial do toque para princesas. 
Há, portanto, uma associação privilegiada entre a tribuna - que nas festas do Divino é o território por excelência da contenção e da hierarquia cerimoniais - e as entidades - voduns e orixás, nobres e princesas - que no tambor de mina estão também associadas à ideia de hierarquia e solenidade.

Inversamente, o mastro - que nas festas está conectado com ideias de excesso e transgressão - é por excelência o território em que se movem os caboclos, associados também eles a ideias de farra e desmesura. De fato, entre as centenas de participantes que se integram no buscamento, no levantamento e no derrubamento do mastro, os caboclos, em particular os farristas, ocupam lugar de destaque. Como já referi, se muitos deles estão ligados ao terreiro que promove a festa, outros provêm de vários terreiros com os quais a casa que organiza a festa mantém relações de reciprocidade cerimonial. Nos casos mais significativos o número de caboclos farristas pode atingir várias dezenas. São facilmente identificáveis tanto pelo vestuário estranho como pelo comportamento hedonista e excessivo, pela licenciosidade verbal e pelo gosto por "farra" e bebida. De forma geral, mantêm-se na festa depois do levantamento e do derrubamento do mastro, ocupando geralmente uma ou mais mesas próprias, onde - para citar uma formulação inspirada em Seth Leacock (I964: I00) - "cantam, dançam, fumam cigarros, bebem cachaça, dizem piadas", fazendo com que o ambiente de farra se prolongue noite afora. ${ }^{9}$

Por meio desse seu comportamento, os caboclos farristas não só se evidenciam como o grupo de protagonistas da festa que melhor se identifica com o espírito excessivo dos segmentos relacionados ao mastro, como definem um modelo de comportamento que, por contágio, é seguido pela maioria dos demais participantes. Nessa medida, a sua presença é essencial para que o buscamento, o levantamento e o derrubamento do mastro se coloquem do lado da antiestrutura.

Isso mesmo é evidenciado em algumas festas em que a presença dos caboclos farristas é mais discreta. Embora as razões para o fato sejam variáveis, elas têm a ver em muitos casos com políticas de respeitabilidade definidas por pais e mães de santo cujos terreiros procuram atrair audiências de classe média negra ou mais próximas do catolicismo institucional. É o caso de pai Clemente, que não gosta - nas suas próprias palavras - desse "monte de caboclo bêbado falando pornografia". As razões têm a ver com a audiência que festa atrai:

Eu não gosto. [...]. Como eu tenho muita gente de fora... E tenho padres, vem padres para cá, e tenho amigos que são católicos ranzinzas. [...]. Eu não gosto. Eu gosto de cada qual no que é seu. Aqui, ele [o caboclo] não tem que fazer, então eu não gosto, como eu vejo em muitas casas, que o mastro derrubando e o encantado está atuado.

Em outros casos, como na Casa das Minas, o menor relevo dos caboclos nos segmentos rituais relacionados com o mastro tem a ver tanto com o estilo puritano que caracteriza a casa (Ferretti, I995) quanto com a capacidade de atração da festa do Divino relativamente a pessoas da classe média negra de São Luís. 
Seja como for, o que é importante reter é que nos casos em que os caboclos farristas têm uma participação mais discreta no buscamento, no levantamento e no derrubamento do mastro, esses segmentos rituais perdem parte de sua capacidade de expressar a brincadeira, a desmesura e o excesso a que surgem associados em outros terreiros. Pode-se, portanto, dizer que a participação dos encantados nas festas do Divino tem características performativas. Ela é de fato decisiva - como mostra o caso do mastro sem caboclos - para que as ideias de solenidade e hierarquia, por um lado, e de desordem e transgressão, por outro lado, se tornem mais efetivas nas festas.

Em suma, as festas do Divino preveem não apenas a intervenção de entidades do tambor de mina na sua organização, como a sua participação na sequência ritual das festas, englobando tanto os rituais mais solenes como os que são marcados pela brincadeira e pelo excesso. Elas não só trazem o Divino para junto dos homens e das mulheres, como trazem também para junto deles os encantados.

Segundo Sergio Ferretti (comunicação oral, 20I2), esse ponto é elaborado, na Casa das Minas, por referência a algumas características centrais da encantaria: um lugar onde não há festas e que seria um mundo triste. Alguns pais de santo ou entidades com quem falei têm uma perspetiva mais cética em relação ao mundo dos encantados como sendo um mundo "triste", mas admitem de qualquer forma o gosto que as entidades têm pela festa: não apenas pela festa do Divino, mas pela festa em geral.

Um dos encantados que baixa em pai Wender - pai de santo da Casa Ilê Ashé Obá Izô - referiu-me esse aspecto:

[os encantados] gostam [...] de vir para dançar e para beber. [Eles gostam de] alegria, brincar, já viu encantado sozinho? [...] Encantado gosta da festa, gosta do movimento, ele gosta de estar no movimento, ele vai ter pessoas na casa, ele gosta de olhar, até a brincadeira, bebida, né? Que é uma coisa que eles gostam muito, tem de fazer essa particularidade, né? Encantado gosta de festa.

O falecido pai Euclides - pai de santo da Casa Fanti-Ashanti - tinha opinião similar:

Entidades gostam da festa? Gostam! Porque vodum e orixá gosta de tudo! É impressionante isso! Vodum gosta muito de acessórios, de adereços e contas, de volta de semente no pescoço, embelezamento do cabelo, vodum gosta de brinco, vodum e orixá gosta de tudo isso! E qualquer manifestação dessas, para eles, é uma coisa diferente, é uma coisa que não é da origem deles. Então, eles se empolgam, se embelezam, acham bonito. E é isso. E então, quando eles chega numa casa dessas que tem festa, que abre o mastro e que é um filho que recebe, ele dá o maior [valor] que, para eles, é uma coisa nova, né? Para eles é uma coisa nova. 


\section{CONCLUSÕES}

Pode-se, portanto, falar de uma congruência estrutural - ou de uma sincronização - entre festas do Divino e tambor de mina construída em torno da oscilação dos dois rituais entre os polos da estrutura e da antiestrutura. Não só ambos se organizam em torno desses dois polos como sua articulação mútua se constrói em cima dessa oscilação, por intermédio de uma sincronização entre segmentos rituais das festas e entidades espirituais do tambor de mina colocadas ora do lado da ordem, ora do lado da transgressão.

Essa congruência é fundamental para a apropriação das festas do Divino pelos terreiros de tambor de mina. De fato, das várias articulações que conectam as festas do Divino ao tambor de mina (Leal, 20I7), é a participação dos encantados nos territórios rituais da tribuna e do mastro que torna mais evidente o modo como as festas definem um espaço de fronteiras porosas, em que convergem devoção e obrigação, mineiros e católicos, encantados do tambor de mina e entidades espirituais católicas. Essa participação cobre, por um lado, os dois territórios fundamentais da festa: a tribuna e o mastro. E diz respeito, por outro lado, não a uma ou outra entidade isolada, mas aos principais tipos de encantados que se manifestam no tambor de mina, tanto os mais "espirituais", como os que estão mais perto da "matéria".

Essa congruência repousa - como em outros casos usualmente tematizados por meio do conceito de sincretismo - sobre modos de compatibilização entre gêneros religiosos diferentes. Enquanto, porém, nos casos mais usuais do chamado sincretismo afrocatólico essa compatibilização intervém entre entidades espirituais de matriz africana e entidades espirituais católicas, nesse caso intervém entre princípios organizadores da atividade ritual comuns à mina e às festas do Divino. Não são entidades que são compatibilizadas, mas sim o modo como ambos os rituais - Divino e mina - oscilam entre os polos da ordem e da desordem.

Esse ponto deve ser enfatizado. Apesar dos inúmeros artigos e debates que suscitou (e continua a suscitar), o tema da articulação entre religiões de matriz africana e outros gêneros religiosos (com destaque para o catolicismo) produziu um catálogo pobre e repetitivo de formas, muitas vezes reduzido às equivalências entre orixás africanos e santos católicos. O que o presente caso sugere é que esse catálogo de formas pode ser ampliado. Um segundo ponto deve também ser destacado. Nas discussões clássicas sobre o chamado sincretismo afrocatólico, o enfoque foi muitas vezes colocado em dois desfechos: a fusão (ou a síntese), ou a mera coexistência - sem efetiva interação - de formulações religiosas distintas. Foi nesses termos que Roger Bastide (2000) distinguiu entre "sincretismo mágico" - por fusão ou síntese - e "sincretismo religioso" - este último operando com base no princípio do corte. A participação dos encantados nas festas do Divino não parece obedecer a nenhuma dessas lógicas. Ela ignora o "princípio do corte”, uma vez que faz convergir nos mesmos 
territórios rituais entidades católicas e encantados; mas não deriva daí fusão ou síntese: as conexões entre Divino e mina aproximam dois gêneros religiosos que mantêm suas diferenças. Como me disse uma caixeira, "Divino é Divino, mina é mina". Por isso, em outro texto, preferi ao conceito de sincretismo - que meus interlocutores não usam a propósito das festas do Divino em terreiros de tambor de mina - a expressão "modos de articulação" (Leal, 20I7). Não só ela me parece captar melhor os tipos de conexão que se estabelecem nas festas do Divino entre rituais e entidades espirituais do catolicismo e do tambor de mina, como o recurso ao plural destaca simultaneamente a diversidade dessas conexões e o modo diferenciado como cada terreiro as gerencia.

Recebido em Io/2/20I9 | Aprovado em 4/4/20I9

João Leal é doutorado em antropologia pelo ISCTE-IUL (Lisboa). É professor na Faculdade de Ciências Sociais e Humanas (UNL) e investigador no CRIA (Nova FCSH). Suas áreas de interesse são o estudo do ritual e da performance e a história da antropologia. Entre suas publicações conta-se O culto do Divino. Migrações e transformações (2019). 


\section{NOTAS}

I Deve ser também enfatizada a importância da pesquisa de Mundicarmo Ferretti (2000) sobre a Casa Fanti-Ashanti. Os títulos citados são os mais conhecidos e que tiveram circulação mais ampla. A eles se somam outros, de circulação mais restrita, como os de Maria Amália Barretto (I977, I987), Maria do Rosário Santos e Manoel dos Santos Neto (I989) e, mais recentemente, David Halperin (I995) e Nicolau Parés (I997).

2 A associação das diferentes entidades do tambor de mina aos polos da estrutura e da antiestrutura foi enfatizada por Halperin (I995).

3 Esses terreiros organizam-se de acordo com o modelo que Nicolau Parés (I997: 3) designa como "mina do caboclo", hoje em dia dominante na maioria das casas de mina de São Luís e marcado não só pela importância dos caboclos entre as entidades espirituais cultuadas, mas também pela sua capacidade de agregação de outras entidades espirituais. A abertura desses terreiros a rituais originários da pajelança é também importante. Deve-se destacar que a expressão "mina de caboclo" não corresponde a uma expressão emic usada pelos próprios "mineiros".

4 Uma apresentação mais detalhada das festas do Divino em São Luís, pode ser encontrada em Ferretti (1995; 1999) e em Leal (20I7). A descrição mais sintetizada que apresento neste artigo resulta de observações realizadas em vários terreiros, onde, apesar de algumas variações, as festas apresentam roteiro ritual dotado de alguma constância.

5 Designação local dada a esse segmento ritual.

6 Sobre o panteão do tambor de mina, ver Mundicarmo Ferretti (2000).

7 Os caboclos farristas foram descritos por Seth e Ruth Leacock na sua monografia sobre o batuque de Belém do Pará (Leacock \& Leacock, I975: 66-67), que não só tem a sua origem histórica no tambor de mina maranhense como possui com ele inúmeras similitudes. Em outro artigo, Seth Leacock (I964: I00) assim os caracterizou: "A sua natureza farrista expressa-se em comportamentos diversificados, incluindo uma marcada predileção por cantar, 
dançar, fumar cigarros, beber cachaça, fazer piadas [...], usar vestuário estranho, e em geral comportar-se de um modo alegre e brincalhão. Eles são, de algum modo, a própria antítese dos senhores, embora com eles partilhem o mesmo poder sobrenatural".

8 Os dados relativos à Casa de Iemanjá reportam-se a 2013, ano em que Toy Agongono era recebido pela mãe de santo agora falecida. Em 20I4, a coroa só foi recebida por dom Lauro das Mercês.

9 Essa associação dos caboclos farristas a comportamentos caracterizados pelo excesso e pela desmesura pode dar lugar a conflitos. Por isso, num dos terreiros que estudei - a casa Ilê Ashé Obá Izô - realiza-se antes do levantamento do mastro uma passagem de cura de forma a evitar "choques de corrente" entre as diferentes entidades presentes. Uma passagem de cura é uma versão mais abreviada do ritual de cura - originário da pajelança - que dá continuamente passagem, num ritmo rápido, a entidades de várias linhas que se vão incorporando sucessivamente no pai de santo. Sobre a cura no tambor de mina, ver Parés (I997: 202-203). Sobre a cura na pajelança cabocla, ver, entre outros, Pacheco (2004) e Laveleye (2010).

\section{REFERÊNCIAS BIBLIOGRÁFICAS}

Barbosa, Marise. (2006). Umas mulheres que dão no couro. As caixeiras do Divino no Maranhão. São Paulo: Empório de Produções e Comunicações.

Barretto, Maria Amália. (1987). A Casa de Fanti-Ashanti em São Luís do Maranhão. Tese de Doutorado. PPGAS/Universidade do Estado do Rio de Janeiro.

Barretto, Maria Amália. (1977). Os voduns do Maranhão. São Luís: Fundação Cultural do Maranhão.

Bastide, Roger. (2000) [1965]. Le syncrétisme mystique en Amérique Latine. In: Bastide, Roger. Le prochain et le lointain. Paris: L'Harmattan, p. 237-24I.

Bastide, Roger. (I960). Les religions africaines au Brésil. Paris: PUF.

Bataille, Georges. (1967). La part maudite. Paris: Les Éditions de Minuit. 
Bitter, Daniel. (2010). A bandeira e a máscara. A circulação de objetos rituais nas folias de reis. Rio de Janeiro: 7 Letras. Chaves, Wagner Diniz. (2013). Na jornada de santos reis. Conhecimento, ritual e poder na Folia do Tachico. Maceió: Edufal. Duvignaud, Jean. (1973), Fêtes et civilizations. Genève: Weber. Eduardo, Octávio da Costa. (1948). The negro in Northern Brasil. A study in acculturation. Seattle/London: University of Washington Press.

Engler, Steven \& Brito, Ênio. (2016). Afro-Brasilian and indigenous-influenced religions. In: Schmidt, Bettina \& Steven, Engler (orgs.). Handbook of contemporary religions in Brasil. Leiden: Brill, p. I42-169.

Ferretti, Mundicarmo. (2000). Desceu na guma. O caboclo do tambor de mina em um terreiro de São Luís. A Casa Fanti-Ashanti. São Luís: Edufma.

Ferretti, Sergio. (2009) [1985]. Querebentã de Zomadônu. Etnografia da Casa das Minas do Maranhão. Rio de Janeiro: Pallas.

Ferretti, Sergio. (2007). Sincretismo e religião nas festas do Divino. Comunicação apresentada ao Encontro Internacional sobre o Divino, São Luís, Sesc. Disponível em <http://www.gpmina.ufma.br/pastas/doc/Sincretismo\% 20a\%20Festa\%20do\%2oDivino.pdf>. Acesso em 7 jul.2007.

Ferretti, Sergio. (2005). Festa do Divino no Maranhão. In: Carvalho, Luciana (org.). Divino toque do Maranhão. Rio de Janeiro: Centro Nacional de Folclore e Cultura Popular/ Iphan, p. 23-3I.

Ferretti, Sergio. (2002). Tambor de crioula, ritual e espetáculo. São Luís: Comissão Maranhense de Folclore.

Ferretti, Sergio. (I999). La fête du divin chez le tambour de mina. Comunicação apresentada à XXV conferência da Société Internationale de Sociologie des Religions. Disponível em: htpp//www.ufma.br/canais/gpmina/textos/ıo. htm. Acesso em 7 jul.2007.

Ferretti, Sergio. (I995). Repensando o sincretismo. Estudo sobre a Casa das Minas. São Paulo: Edusp/Fapema.

Gonçalves, Jandir \& Leal, João. (20I6). Festas do Espírito Santo no Maranhão: uma aproximação de conjunto. Boletim da Comissão Maranhense de Folclore, 60, p. I0-I7. 
Gouveia, Cláudia. (200I). 'As esposas do Divino'. Poder e prestígio na Festa do Divino Espírito Santo em terreiros de tambor de mina de São Luís - Maranhão. Recife: Dissertação de Mestrado (antropologia). Universidade Federal de Pernambuco. Gouveia, Cláudia. (1997). 'O Reinado de Vó Missã'. Estudo da Festa do Divino em um terreiro de mina. Monografia (curso de ciências sociais). Universidade Federal do Maranhão.

Halperin, Daniel. (1995). Dancing at the edge of chaos. An ethnography of wildness and ceremony in an Afro-Brasilian possession religion. PhD thesis. University of California at Berkeley.

Laveleye, Didier de. (2010). Peuple de La Mangrove. Approche ethnologique d'un espace social métissé (Région de Cururupu - Mirinzal, Maranhão, Brésil). Sarrebuck: Éditions Universitaires Européenes.

Leacock, Seth. (1964). Fun-loving deities in an Afro-Brasilian cult. Anthropological Quarterly, 37/3, p. 94-I09.

Leacock, Seth \& Leacock, Ruth. (1975). The spirits of the deep. A study of an Afro-Brasilian cult. New York: Anchor Press.

Leal, João. (2017). O culto do Divino. Migrações e transformações. Lisboa: Edições 70.

Leal, João. (20II). Azorean identity in Brasil and the United States: arguments about history, culture and transnational connections. Dartmouth, MA: Center for Portuguese Studies and Culture/University of Massachusetts (Dartmouth).

Leal, João. (I994). As festas do Espírito Santo nos Açores. Um estudo de antropologia social. Lisboa: Publicações Dom Quixote.

Oliveira, Jorge Itaci. (I989). Orixás e voduns nos terreiros de mina. São Luís: Secretaria de Estado da Cultura.

Pacheco, Gustavo. (2004). Brinquedo de cura. Um estudo sobre a pajelança maranhense. Tese de Doutorado. PPGAS/ Universidadae Federal do Rio de Janeiro.

Pacheco, Gustavo; Gouveia, Claudia \& Abreu, Maria Clara. (2005). Caixeiras do Divino Espírito Santo de São Luís do Maranhão. Rio de Janeiro: Associação Cultural Caburé.

Parés, Luis Nicolau. (1997). The phenomenology of spirit possession in the tambor de mina (an ethnographic and audio-visual study). PhD thesis. SOAS/University of London. 
450

Pereira, Nunes. (1979) [1947]. A Casa das Minas. Contribuição ao estudo das sobrevivências do culto dos voduns do panteão daomeano, no estado do Maranhão, Brasil. Petrópolis: Vozes. Sanchis, Pierre. (1983). Arraial, festa de um povo. As romarias portuguesas. Lisboa: Publicações Dom Quixote.

Santos, Maria do Rosário Carvalho \& Santos Neto, Manoel dos. (1989). Boboromina. Terreiros de São Luís. Uma interpretação sociocultural. São Luís: Secma/Sioge.

Serra, Ordep. (1995). Águas do rei. Petrópolis: Vozes/ Koinonia.

Turner, Victor. (1969). The ritual process. Structure and anti-structure. Chicago: Aldine. 
Palavras-chave

Festa;

religiões afro-brasileiras;

Espírito Santo; tambor de mina;

Maranhão.

Keywords

Festivals;

Afro-Brasilian religions;

Holy Ghost; tambor de mina;

Maranhão.

\section{OS ENCANTADOS NAS FESTAS DO DIVINO:} ESTRUTURA E ANTIESTRUTURA

Resumo

Anualmente realizam-se em São Luís (Maranhão) cerca de 80 festas do Divino Espírito Santo, a maioria em terreiros de tambor de mina e envolvendo a construção de articulações várias entre as festas e entidades e rituais afrorreligiosos. Neste artigo centro-me na participação dos encantados (voduns, orixás, nobres, princesas e caboclos) em distintos segmentos rituais das festas, situados ora do lado da estrutura, ora do lado da antiestrutura. Mostro que essa participação se faz de acordo com a divisão dessas entidades em dois grandes grupos, também eles situados do lado da estrutura (voduns, orixás, nobres e princesas) e do lado da antiestrutura (caboclos). Pode-se, portanto, falar em congruência estrutural entre as festas do Divino e os grandes princípios organizadores do panteão e do ritual do tambor de mina. Argumento que essa congruência é ativamente construída pelos terreiros e é central para entender os processos de apropriação das festas pelo tambor de mina.

\section{THE ENCHANTED IN FESTIVALS OF THE HOLY GHOST: STRUCTURE AND ANTI-STRUCTURE}

\section{Abstract}

Most of the eighty Holy Ghost festivals that take place every year in São Luís (Maranhão) are celebrated in tambor de mina cult houses and involve the construction of several types of articulation between the festivals and Afro-Brazilian ritual. This paper focuses on the participation of encantados ('the enchanted': voduns, orishas, nobles, princesses and caboclos) in distinct ritual segments of Holy Ghost festivals, associated with ideas of structure and anti-structure. I show that the participation of the enchanted in the festivals follows the same pattern: spiritual entities associated with ideas of structure (voduns, orishas, nobles and princesses) participate in rituals organized according to ideas of containment and hierarchy, while other spiritual entities associated with ideas of antistructure (caboclos) participate in rituals organized around the ideas of excess and disorder. Thus a structural congruence exists between Holy Ghost festivals and the principles that organize the tambor de mina pantheon. I argue that this congruence is actively constructed by tambor de mina cult houses and is crucial to understanding the processes through which the Holy Ghost festivals are appropriated. 